\title{
KUALITAS DAN KAPASITASI SPERMATOZOA SAPI BALI, MADURA, DAN PERANAKAN ONGOLE
}

\author{
Aulia Puspita Anugra Yekti ${ }^{1}$, Willy Saputra Tatulus ${ }^{2}$, Dian Ratnawati ${ }^{1}$, Luqman \\ Affandhy $^{1}$, Kuswati ${ }^{1}$, Asri Nurul Huda ${ }^{1}$, Trinil Susilawati ${ }^{1}$ \\ ${ }^{1}$ Fakultas Peternakan Universitas Brawijaya \\ ${ }^{2}$ Loka Penelitian Sapi Potong Grati Pasuruan \\ e-mail : trinil_susilawati@yahoo.com
}

\begin{abstract}
ABSTRAK
Tujuan penelitian ini adalah untuk mengetahui perbedaan kualitas dan kapasitasi spermatozoa pada sapi potong lokal. Selain itu, penelitian ini juga diharapkan dapat digunakan sebagai standar uji kualitas semen. Bahan yang digunakan dalam penelitian ini adalah dua ekor sapi jantan ongole, sapi bali dan sapi madura. Hasil penelitian menunjukkan bahwa persentase motilitas spermatozoa sapi bali 70,83 $\pm 2,04 \%$, sapi madura $70,00 \pm 0,00 \%$ dan sapi PO $71,67 \pm 2$, $58 \%$. persentase Viabilitas spermatozoa sapi bali adalah $89,39 \pm 2,84 \%$, sapi madura $90,60 \pm$ $3,13 \%$ dan sapi PO $92,13 \pm 2,08 \%$. Persentase abnormalitas spermatozoa sapi bali adalah $3,48 \pm 1,09 \%$, sapi madura $2,13 \pm 0,86 \%$ dan sapi PO 2,86 $\pm 0,51 \%$. Konsentrasi sperma sapi bali $1126,67 \pm 169,08$ juta/mL, sapi madura $1076,67 \pm 3,94$ juta/mL dan sapi PO $1210 \pm 160,87$ juta/mL. Total spermatozoa motil pada sapi bali adalah $3136,9 \pm 653,4$ juta/mL, sapi madura $3520,41 \pm 357,48$ juta dan sapi PO $3653,83 \pm 1293,59$ juta $/ \mathrm{mL}$. Persentase status akrosom spermatozoa adalah $85,72 \pm 1,72 \%$, sapi madura $85,35 \pm 0,76 \%$ dan sapi PO $86,40 \pm 1,97 \%$. Data yang didapatkan dalam penelitian ini dianalisis menggunakan rancangan acak lengkap dimana hasil analisa menunjukkan tidak ada perbedaan kualitas yang signifikan $(\mathrm{P}>0,05)$. Dapat disimpulkan perbedaan jenis pada sapi lokal tidak berpengaruh pada kualitas dan kapasitas spermatozoa, tetapi sapi PO memiliki persentase yang lebih tinggi dari kualitas dan kapasitasi sperma dibandingkan sapi bali dan sapi madura.
\end{abstract}

Kata kunci : kualitas semen, spermatozoa, kapasitasi, sapi lokal

\begin{abstract}
The purpose of this research was to determine the differences in the quality and capacitation of local beef cattle sperm. In addition, this study was also expected to be used as a standard of semen quality test. The material used in this study were two bulls of crossbreed ongole, bali cattle and madura cattle. The results of this study revealed that percentage of motility sperm bali cattle $70.83 \pm 2.04 \%$, madura cattle $70.00 \pm 0.00 \%$ and PO cattle $71.67 \pm$ $2,58 \%$. percentage of Viability sperm of bali cattle was $89.39 \pm 2.84$, madura cattle $90.60 \pm$ $3.13 \%$ and PO cattle $92.13 \pm 2.08 \%$. Percentage of abnormality sperm bali cattle were $3.48 \pm$ $1.09 \%$, madura cattle $2.13 \pm 0.86 \%$ and PO cattle $2.86 \pm 0.51 \%$. percentage of concentration sperm bali cattle $1126.67 \pm 169.08$ million / mL, madura cattle $1076.67 \pm 73.94$ million / mL and PO cattle $1210 \pm 160.87$ million / mL. percentage of total motile sperm bali was $3136.9 \pm$ 653.4 million / $\mathrm{mL}$, madura cattle $3520.41 \pm 357.48$ million and $\mathrm{PO}$ cattle $3653.83 \pm 1293.59$ million / $\mathrm{mL}$. percentage of status acrosom sperm is $85.72 \pm 1.72 \%$, madura cows $85.35 \pm 0.76$ and cattle PO $86.40 \pm 1.97$. Data of this research was analyzed using Block Randomized Design (BRD) which showed not significant differences in quality $(\mathrm{P}>0.05)$. The conclusion based on the observations made in this research, differences in local cattle have no effect on the quality and capacitation of spermatozoa, but cross breed ongole cattle have a higher percentage of quality and capacitation of sperm than bali cattle and madura cattle. Semen of bali cattle, and madura cattle used in this study can be used for artificial insemination.
\end{abstract}

Keywords: semen quality, sperm capacitation, local cattle 


\section{PENDAHULUAN}

Berdasarkan data Direktorat Jenderal Peternakan dan Kesehatan Hewan (Ditjen $\mathrm{PKH}$ ) populasi sapi potong berkisar 16.559.00 ekor. Dari populasi tersebut, terdiri beberapa rumpun sapi asli, lokal dan sapi impor. Beberapa rumpun sapi potong asli dan lokal yang telah ditetapkan Pemerintah antara lain sapi bali, sapi peranakan ongole (PO), sapi aceh, sapi madura, sapi Pesisir, sapi sumbawa, sapi jabres dan sapi pasundan (Ditjen PKH, 2017).

Produksi daging yang masih belum mencukupi kebutuhan dalam negeri disebabkan populasi sapi potong yang masih belum mengalami peningkatan, sehingga diperlukan suatu upaya untuk meningkatkan populasi dan produktivitas sapi potong lokal untuk menghasilkan produksi daging dan keturunan yang memliki sifat unggul. Salah satu upaya mewujudkan peningkatan populasi dan produktivitas sapi lokal sebagai salah satu plasma nutfah asli Indonesia yaitu dengan cara menggunakan teknologi inseminasi buatan yang memanfaatkan pejantan yang memiliki kualitas genetik yang unggul di atas rata-rata populasinya

(Susilawati, 2013).

Inseminasi buatan merupakan teknologi yang dapat mengatasi keterbatasan jumlah pejantan unggul serta kapasitas reproduksi pejantan dapat dimanfaatkan secara maksimal (Rizal, 2009). Tingkat keberhasilan inseminasi buatan dipengaruhi beberapa faktor salah satunya adalah kualitas semen yang digunakan. Salah satu faktor yang mempunyai pengaruh terhadap kualitas semen adalah bangsa dari pejantan yang ditampung (Rahmawati et al, 2015). Di dalam proses produksi semen dibutuhkan standardisasi kualitas semen sebelum dibekukan, pada umumnya sapi ditampung seminggu dua kali degan menggunakan vagina buatan (Zamuna et al, 2016 ${ }^{\mathrm{a}}$. Masing-masing individu bangsa sapi terdapat perbedaan volume dan motilitas yang sangat nyata (Zamuna et al., 2016 ${ }^{\mathrm{b}}$ ).

Berdasarkan uraian tersebut, maka penelitian ini bertujuan untuk mengetahui pengaruh bangsa dari pejantan yang ditampung terhadap kualitas dan kapasitasi spermatozoa pada sapi bali, sapi madura dan sapi peranakan ongole.

\section{MATERI DAN METODE}

Penelitan ini dilaksanakan di Laboratorium Loka Penelitian Sapi Potong di Jl. Pahlawan, Grati Pasuruan, Jawa Timur. Materi yang digunakan pada penelitian ini adalah bangsa pejantan sapi lokal yang digunakan pada penelitian ini yaitu dua pejantan sapi PO dengan umur enam dan delapan tahun, bobot badan 532,5 $\mathrm{kg}$ dan 647 $\mathrm{kg}$, lingkar testis $37 \mathrm{~cm}$ dan $41 \mathrm{~cm}$, pejantan sapi bali masing-masing dengan umur lima tahun, bobot badan $440 \mathrm{~kg}$ dan $507 \mathrm{~kg}$, lingkar testis $25 \mathrm{~cm}$ dan $26 \mathrm{~cm}$, dua pejantan sapi madura dengan umur lima dan tiga tahun, bobot badan $397,5 \mathrm{~kg}$ dan $360,5 \mathrm{~kg}$, lingkar testis $31 \mathrm{~cm}$ dan $33 \mathrm{~cm}$. Metode Penelitian ini adalah observasional yaitu untuk mengetahui perbedaan kualitas dan kapasitasi spermatozoa, masing-masing diulang $10 \mathrm{kali}$ penampungan.

Data yang didapat kemudian dihitung menggunakan analisis statistik Rancangan Acak Kelompok (RAK) untuk mengetahui perbedaan antar individu ternak selanjutnya untuk mengetahui semen yang digunakan sesuai dengan standar SNI dihitung dengan person chi square.

\section{HASIL PENELITIAN}

\section{Kualitas Semen}

Kualitas semen bangsa sapi lokal yang digunakan dalam penelitian ini adalah yang memiliki motilitas di atas $70 \%$. Kualitas semen yang didapatkan pada penelitian ini dapat dlihat pada tabel 1 .

Hasil pengamatan makroskopis pada semen segar bangsa sapi lokal yang dilakukan dalam penelitian ini didapatkan rataan volume semen segar masing-masing bangsa sapi lokal yaitu sapi bali $3,75 \pm 0,49 \mathrm{ml}$, sapi Madura 4,57 $\pm 0,61 \mathrm{ml}$, sapi Peranakan Ongole 4,17 $\pm 1,17 \mathrm{ml}$, volume semen sapi madura dan sapi peranakan ongole yang digunakan masih dalam kisaran normal, sedangkan volume semen sapi bali yang digunakan tidak sesuai dengan standar. 
Garner dan Hafez (2008) menyatakan bahwa volume semen sapi per ejakulasi yaitu sebesar 5-8 ml. Warna semen yang didapatkan pada penelitian ini adalah krem atau putih, warna semen yang didapatkan masih normal. Susilawati (2013) menyatakan bahwa semen normal berwarna putih kekuningan atau putih susu. Menurut Sudarmanto, et al. (2015) menyatakan bahwa semen yang baik harus memerhatikan kondisi pada saat semen segar atau setelah penampungan bahwa semen pada sapi memliki pH 6,45-6,57, konsentrasi semen adalah 1223,7-1961,8, motilitas individu 70 $\%$ dan gerak masa $2+$.

Tabel 1 Kualitas Semen Perbangsa Sapi

\begin{tabular}{lccc}
\hline Parameter & Sapi Bali & Sapi Madura & Sapi Peranakan Ongole \\
\hline Makroskopis & Krem & Putih & Krem \\
Warna & $3,75 \pm 0,49$ & $4,57 \pm 0,61$ & $4,17 \pm 1,17$ \\
Volume & $6,63 \pm 0,08$ & $6,57 \pm 0,14$ & $6,47 \pm 0,10$ \\
Ph & Khas & Khas & Khas \\
Bau & Sedang & Sedang & Kental \\
Konsitensi & ++ & ++ & ++ \\
Mikroskopis & $70,83 \pm 2,04$ & $70,00 \pm 0,00$ & $71,67 \pm 2,58$ \\
Motilitas Massa & $89,94 \pm 2,84$ & $90,98 \pm 3,13$ & $92,13 \pm 2,08$ \\
Motilitas Individu & $3,57 \pm 1,19$ & $2,03 \pm 0,94$ & $2,69 \pm 0,55$ \\
Viabilitas & $1140 \pm 158,32$ & $1068,57 \pm 70,81$ & $1210 \pm 160,87$ \\
Abnormalitas & & & \\
Konsentrasi & & & \\
\hline
\end{tabular}

Penilaian rataan terhadap motilitas dibedakan menjadi 2 yaitu motilitas masssa dan motiltas individu. Pada peneltian ini nilai motilitas massa yang didapatkan dari masingmasing sapi bangsa lokal yaitu $2+$, sedangkan rataan motilitas individu yang didapatkan dari masing-masing bangsa yaitu sapi bali 70,71 \pm $1,89 \%$, sapi Madura $70 \%$, sapi peranakan ongole $71,67 \pm 2,585 \%$. Rataan nilai motilitas massa dan motilitas individu bangsa sapi lokal yang digunakan pada penelitian ini sudah sesuai dengan standar. Susilawati (2013) menyatakan semen yang mempunyai persentase motilitas di atas $70 \%$ lebih tahan hidup dibandingkan bila rendah dari $70 \%$. Banyak faktor yang mempengaruhi perbedaan nilai motilitas spermatozoa diantaranya umur, bangsa, kematangan spermatozoa, dan kualitas plasma spermatozoa (Komariah et al.., 2013).

Rataan viabilitas yang didapatkan dari masing-masing bangsa sapi lokal dalam penelitan ini adalah sapi bali $89,94 \pm 2,84 \%$, sapi madura 90,98 $\pm 3,13 \%$ dan sapi PO 92,13 $\pm \quad 2,08 \%$. Persentase viabilitas yang didapatkan masih dalam kisaran normal dan tergolong tinggi hal ini sesuai dengan pendapat Garner dan Hafez (2008) bahwa viabilitas spermatozoa yang baik minimal $80 \%$. Persentase abnormalitas spermatozoa dari masing-masng bangsa sapi lokal adalah sapi bali 3,57 $\pm 1,19 \%$, sapi madura 2,03 \pm $0,94 \%$, sapi PO 2,69 $\pm 0,55 \%$ menunjukkan bahwa semen segar yang digunakan sudah sesuai dengan standar dan layak untuk diproses lebih lanjut. Hal ini sesuai dengan pendapat Susilawati (2011) yang menyatakan bahwa abnormalitas spermatozoa tidak boleh melebihi $20 \%$.

Persentase konsentrasi yang didapatkan pada penelitian ini adalah sapi bali $1140 \pm 158,32 \mathrm{juta} / \mathrm{mL}$, sapi madura 1068,57 $\pm 70,81 \mathrm{juta} / \mathrm{mL}$, sapi PO $1210 \pm 160,87$ juta/mL yang menunjukkan bahwa nilai konsentrasi tersebut sudah sesuai dengan standar yaitu di atas $1000 \mathrm{juta} / \mathrm{mL}$. Garner and Hafez, 2008 menyatakan bahwa konsentrasi semen sapi bervariasi dari 1000-1800 juta spermatozoa tiap mililiter atau 800- 2000 juta spermatozoa tiap mililiter. 


\section{Motilitas Individu}

Motilitas spermatozoa adalah salah satu kriteria penentu kualitas spermatozoa yang dilihat dari banyaknya spermatozoa yang bergerak progresif, dengan maksud agar sampai di dalam alat reproduksi betina untuk fertilisasi.

Hasil analisis ragam menunjukkan bahwa masing-masing individu tidak memberikan pengaruh yang nyata $(\mathrm{P}>0.05)$ terhadap motilitas individu, sedangkan berdasarkan hasil analisis dengan menggunakan person chi square menunjukkan tidak berbeda nyata $(\mathrm{P}>0.05)$ artinya bahwa nilai yang didapatkan mendekati dengan nilai harapan untuk IB yaitu motilitas spermatozoa sebesar 70\% dapat digunakan untuk proses inseminasi buatan. Hal ini berbeda dengan hasil penelitian Rahmawati, et al. (2015) yang menyatakan bahwa perbedaan bangsa sapi potong memberikan pengaruh yang nyata terhadap motilitas individu. Rataan persentase motilitas spermatozoa pada masing-masing bangsa sapi lokal dapat dilihat pada Tabel 2.

Berdasarkan Tabel 2 menunjukkan bahwa rataan motilitas individu sapi lokal yaitu sebesar 70\%. Persentase motilitas tertinggi yaitu pada sapi PO sebesar 71,67\%, sedangkan persentase motilitas terendah yaitu pada sapi madura sebesar $70 \%$.

Tabel 2. Rataan Motilitas Spermatozoa Pada Sapi Bali, Sapi Madura dan Sapi PO

\begin{tabular}{ll}
\hline Bangsa & Rata-rata \pm SD (\%) \\
\hline Sapi madura & $70,00 \pm 0,00$ \\
Sapi bali & $70,83 \pm 2,04$ \\
Sapi PO & $71,67 \pm 2,58$ \\
\hline
\end{tabular}

Komariah et al. (2013) menyatakan bahwa banyak faktor yang mempengaruhi perbedaan nilai motilitas spermatozoa diantaranya umur, bangsa, kematangan spermatozoa dan kualitas plasma spermatozoa. Hal ini ditambahkan pendapat dari Azzahra et al. (2016) yang menyatakan bahwa perbedaan motilitas spermatozoa dapat disebabkan oleh umur, pada sapi peranakan ongole umur 1,5 tahun memiliki motilitas lebih rendah dibandingakn dengan umur 2 tahun, hal ini karena pada sapi umur 2 tahun organ reproduksi primer dan sekunder sudah optimal.

\section{Viabilitas Spermatozoa}

Pengujian viabilitas dilakukan untuk menguji kerusakan pada bagian kepala spermatozoa. rataan viabilitas spermatozoa selama penelitian menunjukkkan bahwa masing-masing bangsa sapi lokal tidak memberikan pengaruh yang nyata terhadap viabilitas spermatozoa $(\mathrm{P}>0,05)$. Rataan viabilitas spermatozoa masing-masing bangsa sapi lokal dapat dilihat pada tabel 3.

Tabel 3. Viabilitas Spermatozoa Sapi Bali, Sapi Madura dan Sapi PO

\begin{tabular}{lc}
\hline Bangsa & Rataan \pm SD (\%) \\
\hline Sapi bali & $89,39 \pm 2,84$ \\
Sapi madura & $90,60 \pm 3,13$ \\
Sapi PO & $92,13 \pm 2,08$ \\
\hline
\end{tabular}

Berdasarkan hasil pengamatan pada penelitian ini didapatkan persentase rataan viabilitas teringgi yaitu pada sapi PO sebesar $92,13 \%$, sedangkan ratan viabilitas spermatozoa terendah pada sapi bali yaitu sebesar 89,39 \%. Pengamatan viabilitas spermatozoa yaitu dengan cara pengamatan menggunakan mikroskop. Spermatozoa yang hidup ditandai dengan spermatozoa yang tidak berwarna, sedangkan spermatozoa yang mati yaitu yang menyerap pewarna eosin negrosin.. Hal ini disebabkan, karena spermatozoa yang mati membrannya tidak berfungsi sehingga pewarna dapat masuk ke dalam membran spermatozoa (Susilawati, 2011).

Rataan nilai viabilitas spermatozoa yang didapat pada penelitian masih cukup baik. Hal ini sesuai dengan pendaapat Garner dan Hafez (2000) yang menyatakan bahwa persentase semen sapi segar yaitu sekitar $60-$ $80 \%$. Bearden and Fuquay (2000) menyatakan bahwa persentase spermatozoa hidup akan selalu lebih tinggi daripada motilitas spermatozoa.

\section{Abnormalitas Spermatozoa}

Penentuan jumlah dan macam abnormalitas spermatozoa di dalam suatu ejakulat harus dipakai bersamaan dengan pemeriksaan-pemeriksaan lain yang dilakukan segera setelah penampungan semen 
seperti penetuan motilitas, konsentrasi dan jumlah spermatozoa yang hidup dan mati. Perbedaan bangsa sapi lokal pada penelitian tidak memberikan pengaruh yang nyata pada nilai abnormalitas spermatozoa $(\mathrm{P}>0.05)$. Rataan nilai abnormalitas dari masing-masing bangsa sapi lokal dapat dilihat pada Tabel 4.

Tabel 4 Rataan Abnormalitas Sapi Bali, Sapi Madura dan Sapi PO

\begin{tabular}{lc}
\hline Bangsa & Rataan \pm SD $(\%)$ \\
\hline Sapi bali & $3,48 \pm 1,09$ \\
Sapi madura & $2,13 \pm 0,86$ \\
Sapi PO & $2,86 \pm 0,51$ \\
\hline
\end{tabular}

Berdasarkan hasil pengamatan pada tabel 4 sapi lokal yang mempunyai nilai abnormalitas yang terendah yaitu ada sapi madura yaitu sebesar $2,13 \%$. Sedangkan nilai rataan abnormalitas terbesar pada sapi bali yaitu sebesar 3,48 \%. Nilai rataan abnormlitas yang didapatkan dalam penelitian ini masih cukup baik karena nilai rataan abnormalitas spermatozoa masih di bawah $20 \%$ sehingga masih layak untuk di proses lebih lanjut untuk insemianasi buatan. Hal ini seuai dengan pendapat Ax et al (2008) yang menyatakan bahwa semen yang mempunyai abnormalitas $15 \%$ tidak dapat di gunakan untuk IB.

Abnormalitas

spermatozoa

merupakan merupakan kelainan struktur spermatozoa dari struktur normal yang dapat disebabkan oleh beberapa faktor yaitu lingkungan, genetik atau kombinasi dari keduanya (Chenoweth, 2005). Beberapa faktor yang dapat memengaruhi abnormalitas spermatozoa salah satunya yaitu pada saat pembentukan spermatozoa dan penanganan semen setelah di tampung. Susilawati (2011) menyatakan bahwa stres terhadap panas yang paling banyak pengaruhnya terhadap kerusakan spermatozoa, selain itu besarnya jumlah spermatozoa yang abnormal juga terjadi pada saat periode recovery.

\section{Konsentrasi Spermatozoa}

Rataan konsentrasi spermatozoa masing-masing bangsa sapi lokal menunjukkan perbedaan yang tidak nyata $(\mathrm{P}>0,05)$. Rataan persentase konsentrasi masing-masing bangsa sapi lokal dapat dilihat pada Tabel 5.

Tabel 5. Rataan Konsentrasi Spermatozoa Sapi Bali, Sapi Madura dan Sapi PO

\begin{tabular}{lc}
\hline Bangsa & Rataan \pm SD (juta/mL) \\
\hline Sapi bali & $1126 \pm 169,08$ \\
Sapi madura & $1076 \pm 73,94$ \\
Sapi PO & $1210 \pm 160,87$ \\
\hline
\end{tabular}

Berdasarkan hasil pengamatan pada tabel 5 didapatkan rataan konsetrasi spermatozoa tertinggi yaitu sapi PO sebesar $1210 \mathrm{juta} / \mathrm{mL}$, sedangkan rataan konsentrasi spermatozoa terendah pada sapi madura yaitu sebesar 1076 juta/mL. Hal ini sesuai dengan pendapat Bearden dan Fuquay (2000) yang menyatakan bahwa konsentrasi sapi potong 1000 juta spermatozoa tiap milliliter.

Penilaian konsentrasi spermatozoa tiap milliliter semen sangat penting, karena faktor ini dipakai untuk sebagai kriteria penentu kualitas semen dan menenetukan tingkat pengencerannya (Susilawati, 2013).

\section{Total Spermatozoa Motil}

Hasil total spermatozoa motil diperoleh dengan cara mengalikan persentase motilitas individu dengan total spermatozoa. Total spermatozoa motil sangat dipengaruhi oleh motilitas dari spermatozoa pada berbagai bangsa (Rahmawati et al., 2015). Perbedaan bangsa sapi lokal tidak memberikan pengaruh yang nyata pada total spermatozoa motil $(\mathrm{P}>0.05)$. rataan persentase total spermatozoa motil dapat dilihat pada tabel 6 .

Tabel 6. Rataan Total Spermatozoa Motil Sapi Bali, Sapi Madura dan Sapi PO

\begin{tabular}{lc}
\hline Bangsa & Rataan \pm SD $(\mathrm{Juta} / \mathrm{mL})$ \\
\hline Sapi bali & $3136 \pm 653,4$ \\
Sapi Madura & $3520 \pm 357,48$ \\
Sapi PO & $3653 \pm 1293,59$ \\
\hline
\end{tabular}

Berdasarkan hasil penelitian Nilai total motilitas spermatozoa motil tertinggi didapatkan oleh sapi PO sebesar $3653 \pm$ 1293,59 juta/ $\mathrm{mL}$ sedangkan nilai total spermatozoa motil yang rendah didapatkan pada sapi bali $3136 \pm 653,4 \mathrm{juta} / \mathrm{mL}$. Hasil penelitian Nyuwita et al. (2015) menyatakan bahwa umur memberikan pengaruh yang berbeda terhadap total spermatozoa motil. 
Semakin meningkatnya umur pada ternak dapat menurunkan persentase motilitas spermatozoa dan konsentrasi spermatozoa yang dihasilkan. Hal ini di dukung oleh Brito et al., (2002) umur memberikan pengaruh yang signifikan terhadap total spermatozoa motil yang dihasilkan. Faktor lain yang ikut berpengaruh selain umur yaitu pada individu ternak.

Faktor lain yang dapat berpengaruh terhadap total spermatozoa motil berdasarkan hasil penelitian Rokhana (2008) yaitu bahwa terdapat hubungan yang significant antara jumlah false mounting dengan total spermatozoa motil semen sapi pejantan.

\section{Status Akrosom Spermatozoa}

Pengamatan status akrosom dapat dilakukan dengan beberapa cara salah satunya yaitu dengan pewarnaan chlortetracyline (CTC) yang diamati dengan menggunakan mikroskop epi fluorescent dengan pembesaran 400 kali. Perbedaan bangsa sapi pada penelitian ini tidak memberikan pengaruh yang nyata terhadap status akrosom yaitu $(\mathrm{P}>0.05)$. Rataan persentase status akrosom spermatozoa masing-masing bangsa sapi lokal dapat dilihat pada Tabel 7.

Tabel 7. Rataan Persentase Status Akrosom Spermatozoa

\begin{tabular}{lccc}
\hline \multicolumn{1}{c}{ Bangsa } & $\begin{array}{c}\text { Belum Kapasitasi } \\
\text { Rataan } \pm \text { SD }(\%)\end{array}$ & $\begin{array}{c}\text { Kapasitasi } \\
\text { Rataan } \pm \text { SD (\%) }\end{array}$ & $\begin{array}{c}\text { Reaksi Akrosom } \\
\text { Rataan } \pm \text { SD (\%) }\end{array}$ \\
\hline Sapi bali & $85,72 \pm 1,72$ & $9,41 \pm 1,41$ & $4,87 \pm 0,05$ \\
Sapi madura & $85,35 \pm 0,76$ & $9,77 \pm 0,95$ & $4,88 \pm 0,93$ \\
Sapi PO & $86,40 \pm 1,97$ & $9,41 \pm 1,35$ & $4,19 \pm 1,02$ \\
\hline
\end{tabular}

Berdasarkan hasil pengamatan selama penelitian didapatkan spermatozoa yang belum kapasitasi dengn nilai tertinggi yaitu sapi PO sebesar $86,40 \%$ dan sapi bali sebesar $85,72 \%$, sedangkan rataan spermatozoa yang belum kapasitasi dengan nilai terendah yaitu sapi madura 85,35\%. Rataan spermatozoa yang belum mengalami kapasitasi yang didapatkan pada penelitian ini masih relatif tinggi, sehingga semen yang digunakan masih layak untuk digunakan IB. Hal ini disebabkan karena proses kapasitasi spermatozoa seharusnya terjadi di saluran reproduksi betina. Hal ini sesuai dengan pendapat Susilawati (2011) yang menyatakan bahwa spermatozoa yang berkapasitasi secara in vivo membuahi sel telur lebih jauh efisien dari in vitro.Proses kapasitasi perlu untuk dapat melakukan penetrasi pada oosit. Sebelum melakukan fertilisasi, spermatozoa harus melakukan migrasi melalui saluran reproduksi betina. Dalam perjalanan ini permukaan spermatozoa dilindungi oleh glikoprotein sebagai pelindung yang disekresi oleh epididimis dan berfungsi melindungi permukaan spermatozoa ketika garnet

diekspos seminal plasma saat ejakulasi. Proses kapasitasi ini harus berjalan secara gradual (bertahap) untuk menghilangkan pelindung tersebut dari permukaan spermatozoa terutama bagian akrosom (Triwulanningsih et al., 2002).

\section{KESIMPULAN}

Berdasarkan hasil pengamatan yang dilakukan pada penelitian ini diketahui bahwa perbedaan bangsa sapi lokal tidak memberikan pengaruh terhadap kualitas dan kapasitasi spermatozoa, tetapi nilai kualitas dan kapasitasi spermatozoa sapi PO lebih tinggi dibandingkan sapi bali dan sapi madura.

\section{UCAPAN TERIMA KASIH}

Ucapan terimakasih r pada
KEMENRISTEKDIKTI yang telah
membantu dana penelitian melalui skema
PUPTN dan Loka Penelitian Sapi Potong
Grati Pasuruan yang telah mengizinkan untuk
melakukan penelitian dan memberikan
fasilitas yang menunjang selama penelitian.




\section{DAFTAR PUSTAKA}

Ax R.L., M.R. Dally, B.A. Didion, R.W. Lenz, C.C. Love, D.D. Varner, B. Hafez \& M.E. Bellin. 2008. Semen Evaluation. Reproductive in Farm Animals. 8th Edition. Edited by Hafez and Hafez.Lea and Febiger: 365-375.

Azzahra, F.Y., E.T. Setiatin, \& D. Samsudewa. 2016. Evaluasi motilitas dan persentase hidup semen segar sapi PO Kebumen pejantan muda. Jurnal Sain Peternakan Indonesia. 11(2): 99107

Bearden, H.J., \& J.W. Fuquay. 2000. Applied Animal Reproduction 5th Ed. Prentice Hall. Upper Saddle River. New Jersey

Brito, L.F.C., A.E.D.F. Silva., L.H. Rodriques., F.V. Vieira., L.A.G. Deragon \& J.P. Kastelic. 2002. Effects of environmental factors, age andgenotype on sperm production and quality in bos indicus and bos taurus AI bulls in Brazil. Animal Reproduction Seience. 70: 181-190.

Chenoweth, P.J. 2005. Genetic sperm defects. Theriogenology 64: 257-468.

Direktorat Jenderal Peternakan dan Kesehatan Hewan. 2017. Bahan Rapat Pimpinan: Supply dan Demand Daging Sapi Tahun 2016-2017. Jakarta (ID): Direktorat Jenderal Peternakan dan Kesehatan Hewan Kementerian Pertanian

Garner, D.L. \& E.S.E. Hafez. 2008. Spermatozoa and Seminal Plasma. In: Reproduction In Farm Animals. E.S.E Hafez and B.Hafez (Edit). 7th ed. Blackwell Publishing. Australia: 96109.

Komariah, I. Arifiantini \& F.W. Nugraha. 2013. Kaji banding kualitas spermatozoa sapi simmental, limousin, dan friesian holstein terhadap proses pembekuan. Buletin Peternakan. $\quad 37(3)$ : 143-147.
Reproduction an Infertility. 6(2): 3540.

Nyuwita, A., T. Susilawati, \& N. Isnaini. 2015. Kualitas semen dan produksi semen beku sapi Simmental pada umur yang berbeda. J. Ternak Tropika. 16(1): 61-68.

Rahmawati, M.A., T. Susilawati, \& M.N. Ihsan. 2015. Kualitas semen dan produksi semen beku pada bangsa sapi dan bulan penampungan yang berbeda. Jurnal Ilmu-Ilmu Peternakan 25 (3): $25-36$

Rizal, M. 2009. Daya hidup spermatozoa epididimis sapi bali yang dipreservasi pada suhu $3-5^{0} \mathrm{C}$ dalam pengencer tris dengan konsentrasi laktosa yang berbeda. Jurnal Ilmu Ternak dan Veteriner. 14(2): 142-149.

Rokhana, E. 2008. hubungan antara jumlah false mounting dengan produksi semen pejantan sapi madura. Jurnal Fillia Cendekia. Edisi Maret. 6(1).

Sudarmanto, T. Susilawati \& N. Isnaini. 2015. Pengaruh lama gliserolisasi terhadap keberhasilan produksi semen beku sapi simmental. Jurnal Ilmu-Ilmu Peternakan 25 (2):43-48

Susilawati, T. 2011. Spermatologi. Universitas Brawijaya Press. Malang.

Susilawati, T. 2013. Pedoman Inseminasi Buatan Pada Ternak. Malang: UB Press. ISBN: 978-602-203-458-2.

Triwulanningsih E., M.R. Toelihere, T.L. Yusuf, B. Purwantara., K. Diwyanto, \& J.J Rutledge. 2002. Seleksi dan kapasitasi spermatozoa dengan metode percoll gradient vkyuk fertilisasi oosit dan produksi embrio in vitro pada sapi.

Zamuna, A.A.K.M, T.Susilawati \& G. Ciptadi 2016a ${ }^{\mathrm{a}}$. Evaluation of different breeds of beef cattle bull's capacity in producing frozen sperms. Research in Zoology 6(1):8-10 
Zamuna ,A.A.K.M, T. Susilawati , G. Ciptadi \& Marjuki. 2016 ${ }^{\mathrm{b}}$. Perbedaan kualitas semen dan produksi semen beku pada berbagai bangsa sapi potong. J. Ternak Tropika 16 (2):01-06. 